\title{
The microstructural and thermal characteristics of silica nanoparticle-modified cement mortars after exposure to high temperatures. Part I
}

\author{
P. Sikora (iD \\ West Pomeranian University of Technology, Szczecin, Poland; \\ Technische Universität Berlin, Germany \\ * Corresponding author: e-mail: pawel.sikora@zut.edu.pl \\ (c) P. Sikora, 2020
}

\begin{abstract}
This study presents an investigation of the effects of high temperature on the thermal and microstructural properties of cement mortars modified with nanosilica. In the first stage of the research, the effects of nanosilica (NS) and silica fume (SF) on the hydration and compressive strength of cementitious composites were compared. In the second stage, four different types of cement mortars, containing an optimal dosage of NS, were produced. Two of them contained a normal weight aggregate (quartz or limestone), whilst two contained a heavy weight aggregate (barite or magnetite). Specimens without NS were produced for control purposes. The specimens were exposed to $300,450,600$ and $800^{\circ} \mathrm{C}$, with their post-heating properties - including thermal conductivity, specific heat, solvent absorption and cracking behavior - analyzed. The results show that NS exhibits significantly higher reactivity with cement than SF. NS accelerates the cement hydration process and contributes more significantly to the 28 and 365 day compressive strength of mortar, as compared to SF. The incorporation of NS in a composite substantially decreases the amount of $\mathrm{CH}$ in the mixture and leads to the production of additional $\mathrm{C}-\mathrm{S}-\mathrm{H}$ gel phase, which improves microstructure. The study also shows that NS contributes to a decrement in the thermal conductivity and density of mortar, both prior to and after heating. The incorporation of NS has a beneficial effect on decreasing the deterioration rate of mortars after heating, by decreasing absorption rate and the amount of cracks in in them.
\end{abstract}

KEYWORDS: cement mortar, nanosilica, elevated temperature, thermal properties, cracking.

ACKNOWLEDGMENTS: Supported by the Foundation for Polish Science (FNP).

FOR CITATION: Sikora P. The microstructural and thermal characteristics of silica nanoparticle-modified cement mortars after exposure to high temperatures. Part I. Nanotechnologies in Construction. 2020, Vol. 12, no. 2, pp. 108-115. DOI: 10.15828/20758545-2020-12-2-108-115.

\section{INTRODUCTION}

$\mathrm{C}$ oncrete and cement mortars are versatile materials which are applied for various construction purposes. Their popularity can be attributed to their satisfactory durability and their stable mechanical performance, over the course of a structure's life. However, inadequate protection of concrete elements, their exposure to corrosion or unexpected, extreme conditions - such as the high temperatures encountered during fires - can lead to their serious damage and even structural collapse. Historically, much research has been undertaken to assess the effects of elevated temperatures on the properties of cementitious composites and to develop ones which are durable and heat resistant. In actual fact, alterations in the properties of cementitious composites start at the very beginning of an element's heating process, with even temperatures of around $100^{\circ} \mathrm{C}$ (the standard concrete drying temperature in laboratory tests) causing noticeable microstructural alterations. In general, three main temperature ranges (zones), having significant effects on the performance of composites, can be distinguished: (1) low $\left(<300^{\circ} \mathrm{C}\right)$, where the mechanical performance of a composite remains quite stable or even improves, (2) intermediate $\left(300-600^{\circ} \mathrm{C}\right)$, where moderate deterioration in mechanical and microstructural properties has been reported and; 
(3) high $\left(>600^{\circ} \mathrm{C}\right)$, where drastic deterioration of composite properties, even leading to a breaking up of specimens into pieces, has been reported [1].

To efficiently analyze concrete's fire-resistance, various parameters, besides the mechanical, should be taken in account; including thermal and deformation properties, as well as fire-induced spalling [2]. Among the thermal parameters, thermal conductivity, specific heat and thermal expansion are all of high importance, as they enable the development of composites' temperature profiles. Kodur et al. [2], for instance, has reported that a $10 \%$ increase in thermal conductivity leads to higher crosssectional temperatures, which result in a lowering of fire resistance by approximately 5\%. Moreover, in order to effectively assess the further performance of a composite after an accident, it is important to take into account postfire properties, such as transport properties and the durability of related parameters.

There are many ways to improve the performance of cementitious composites, including adjusting the cement type, using proper aggregates and incorporating various fibers and admixtures. Modifying cement composition with additives and admixtures has been shown to have a significant impact on decreasing composite deterioration rates. Among the conventional supplementary cementitious materials (SCMs), the inclusion of slag or fly ash in concrete compositions has shown superior property retention after thermal exposure [3, 4]. However, while silica fume (SF) is an excellent pozzolanic additive and shows excellent effects on concrete performance in ambient conditions, its use often has negative effects when a composite is exposed to elevated temperatures [5]. This negative effect is attributable to the significant densification and compaction of concrete microstructure, which leads to severe cracking and increased strength loss after exposure to temperature.

It is therefore very important to choose a mixture composition in which the constituents are stable and compatible, not only in ambient conditions, but also during heating. Furthermore, it is also crucial to evaluate the properties of composites after exposure to temperature (post-heating properties), as their constituents undergo certain physical and chemical changes along with temperature rises.

In recent years, it has been found that nanosized admixtures can be used to improve the thermal resistance of cementitious composites. The progress of recent years has resulted in the availability of many such commercial products, as well as in a significant increase in the amount of patents put forward with the commercialization of these material in mind [6]. Due to their ultrafine size and spectacular surface activity, even a small dose can enable significant modification of composite properties. Among the materials which have been of particular interest to researchers working towards improving the heat resistance of cement-based composites, are silica nanoparticles (NS), carbon nanotubes and iron oxides [4]. Depending on the type of nanoparticles used, in some cases positive effects are a result of chemical interaction between the cement and the nanoparticles; at other times, the positives result mainly from physical interactions, acting as fillers or fibers and thus improving microstructure [4].

The effects of nanomaterials on the thermal resistance of cementitious composites has recently been reviewed by Sikora et al [4]. According to this review, it can be concluded that, to date, most work has focused on analyzing the mechanical characteristics of such composites, with the microstructural, thermal and durability-related properties, after exposure to elevated temperatures, remaining overlooked. However, studies on the effects of NS on the heat resistance of cementitious composites, generally show a trend opposite to the one reported for silica fume. Due to the superior chemical activity of NS, as compared to silica fume and as a result of the reduced dosages of it needed, its use does not have the negative effects of SF. However, research regarding the effects of NS on the thermal and transport properties of cementitious composites is limited and thus requires further investigation.

As a result, this study aims to fill the above-mentioned gap in knowledge and to assess the thermal and microstructural properties of NS-modified cementitious mortars exposed to elevated temperatures. The first part of the experiment, where the effects of nanosilica (NS) and silica fume (SF) on cement hydration were evaluated, showed that there are distinct differences between the effects of NS and SF on the cement hydration process, even in mortars with comparable chemical compositions; and that NS has a significant effect on the mechanical performance of mortars. In the second part of the study, cement mortars with four different types of aggregates, both with and without nanosilica, were produced and exposed to temperatures of $300,450,600$ and $800^{\circ} \mathrm{C}$; their post-heating properties were determined and compared, with the results discussed below.

\section{Materials and methods}

\subsection{Materials}

CEM I 42.5 R, produced by Heidelberg Cement (Germany) and silica fume (SF) obtained from Sika (Germany) were used. Commercially available silica nanoparticles (NS), with an average size of 10-140 nm and a solid content of $50 \mathrm{wt} .-\%$, were used (Table 1). Details of the nanosilica used in this study can be found in the work of Sikora et al. [7]. Four types of aggregates, including normal-weight aggregates (quartz and limestone) and heavy-weight aggregates (barite and magnetite), were used. The density of the quartz, limestone, 
Table 1

Properties of colloidal silica

\begin{tabular}{|c|c|c|c|c|}
\hline Particle size $^{*}$ & Solid content & Density & Viscosity & pH \\
\hline $10-140 \mathrm{~nm}$ & 50 wt. $\%$ & $1.4 \mathrm{~g} / \mathrm{cm}^{3}$ & $8 \mathrm{cP}$ & 9.5 \\
\hline
\end{tabular}

* based on TEM analysis

Table 2

Particle size distribution of aggregates used in this study

\begin{tabular}{|l|c|c|c|c|c|}
\hline Mesh size [mm] & 2.00 & 1.60 & 0.50 & 0.16 & 0.08 \\
\hline Cumulative sieve residue [\%] & 0 & $7 \pm 5$ & $33 \pm 5$ & $67 \pm 5$ & $99 \pm 1$ \\
\hline
\end{tabular}

magnetite and barite aggregates were 2.64, 2.73, 4.77 and $4.20 \mathrm{~g} / \mathrm{cm}^{3}$, respectively. In order to facilitate a comparable particle size distribution for the aggregates used in this study, the aggregates were initially sieved to conform to the specifications of EN 196-1 (Table 2). Standard tap water was used as the mixing water. Due to the initially higher water absorption of the barite aggregate, as compared to the other aggregates, PCE superplasticizer was used, at a dosage of $0.7 \%$ by weight of cement (bwoc), to produce a workable barite aggregate mortar.

\subsection{Mixture design proportions}

Standard mortar mixture designs, with a water-cement ratio $(\mathrm{w} / \mathrm{c}=0.5)$ conforming to EN 196-1, were used. Accordingly, the cement mortars produced in this study had a cement:water:aggregate ratio of 1:0.5:3. NS was used in its liquid form, with $50 \mathrm{wt} .-\%$ of solid mass with the liquid phase of the silica suspension therefore considered as a part of the mixing water. Prior to mixing with the nanosilica, the tap water and plasticizer (if used) were mixed together. An optimal NS dosage of $3 \%$ bwoc was chosen, based on previous studies [7]. The mortars were mixed in a laboratory mixer, following the standard procedure outlined in EN 196-1. After mixing, they were poured into oiled steel moulds to form $20 \times 20 \times 20 \mathrm{~mm}^{3}$ cubes for compressive strength evaluation and $40 \times 40 \times 40$ $\mathrm{mm}^{3}$ cubes for thermal and absorption property tests. Moreover, $40 \times 40 \times 160 \mathrm{~mm}^{3}$ bars were also produced and then cut into smaller pieces for visual inspection. The specimens were designated according to a letter representing the type of aggregate used $(\mathrm{Q}-$ quartz, LS - limestone, B - barite, $\mathrm{M}$ - magnetite), with a digit (0 or 3 ) representing the dosage of NS, in percentage by weight of cement (bwoc). M3, for instance, refers to mortar produced with magnetite aggregate, containing $3 \%$ bwoc of NS.

\subsection{Testing methods}

An isothermal conduction calorimeter (TAM Air 3 calorimeter) was used to evaluate the hydration heat of the cement pastes. $10 \mathrm{~g}$ of cement and $5 \mathrm{~g}$ of water was mixed with NS or SF (if applicable) and then mixed for $60 \mathrm{~s}$. The specimens were immediately placed in calorimeter cells after mixing and then measured for 5 days.

The compressive strength of the mortars was tested on $20 \times 20 \times 20 \mathrm{~mm}^{3}$ specimens, with the use of a Toni Technik testing machine, according to EN 197-1.

Determination of the thermal conductivity and specific heat of the specimens was performed with the transient plane source method (TPS), in accordance with ISO 22007-2. A Hot Disk measuring device with a Kapton-insulated sensor was used for this purpose. After each heating procedure, the specimens were placed in a sealed box containing silica gel, until they cooled, to remove any moisture from them before measurement. Next, the Kapton-insulated sensor was sandwiched between two identical $40 \times 40 \times 40 \mathrm{~mm}^{3}$ specimens. Three specimens were used to test each mortar, with the mean value adopted in each case.

Thermogravimetric analysis (TGA) was performed under a nitrogen atmosphere and at a flow rate of $250 \mathrm{ml} / \mathrm{min}$, using a TG 209 Tarsus F3 (Netzsch). After 28 days of curing, the specimens were ground and immersed in isopropanol to stop any hydration reactions and then dried in freeze-dryer. In the TG procedure, the sample was first held at $25^{\circ} \mathrm{C}$ for $20 \mathrm{~min}$ and then heated from $25^{\circ} \mathrm{C}$ to $1000^{\circ} \mathrm{C}$ at $10.00 \mathrm{~K} / \mathrm{min}$.

To evaluate the effects of NS on the pore structure characteristics of the cement matrix, the mercury intrusion porosimetry (MIP) technique was applied. Measurement was performed on small-cored samples after 28 days of curing, with the use of Pascal 140 and 240 series (Ther- 
mo Scientific) mercury intrusion porosimeters. Mercury density was measured at $13.5450 \mathrm{~g} / \mathrm{mL}$, the surface tension was taken as $0.48 \mathrm{~N} / \mathrm{m}$, while the selected contact angle was $140^{\circ}$. Prior to measurement, the specimens were immersed in isopropanol and then freeze-dried.

The determination of water absorption is a common, indirect testing method which gives good insight into the microstructural changes occurring in cementitious composites, after various durability-related tests are performed. This method is also often applied to characterize the post-fire rate of microstructural deterioration, after exposure to elevated temperatures [8-10]. However, saturating samples in water can cause degradation of the fragile cement matrix microstructure and increase the amount of cracks, thus increasing the water absorption value obtained. To counter this problem, it has been found that replacing water with a solvent such as acetone [8] or ethanol [9] helps to avoid the rehydration of portlandite and the calcium-silicate-hydrate $(\mathrm{C}-\mathrm{S}-\mathrm{H})$ phase, therefore making it possible to estimate absorption much more accurately. Accordingly, to determine water absorption, six $40 \times 40 \times 40 \mathrm{~mm}^{3}$ samples were prepared and subsequently saturated in acetone, for each testing temperature.

The solvent absorption can be calculated according to the following equation (Eq. 1):

$$
\mathrm{W}(\%)=\frac{\mathrm{W}_{\mathrm{sat}}-\mathrm{W}_{\mathrm{dry}}}{\mathrm{W}_{\mathrm{dry}}} \times 100
$$

where $\mathrm{W}(\%)$ is solvent absorption and $\mathrm{W}_{\text {sat }}$ and $\mathrm{W}_{\mathrm{dry}}$ are the weights of the samples in their saturated and dry states, respectively.

\section{Comparison of the effects of NS and SF on the ce- ment hydration process and compressive strength}

\subsection{Isothermal calorimetry}

In the first stage of the research, the results of the calorimetry measurements of specimens containing 3, 5 and $10 \%$ bwoc of nanosilica and silica fume, were compared. Both NS and SF are known to be highly reactive pozzolanic materials, because of their high surface areas and very high amorphous silicon dioxide contents. Therefore, when Portland cement reacts chemically with water, it produces calcium hydroxide which then reacts with the NS or SF, to form additional calcium silicate hydrate $(\mathrm{C}-\mathrm{S}-\mathrm{H})$ gel [11-14]. Moreover, the fine particles of NS and $\mathrm{SF}$ both provide nucleation sites where the products of cement hydration can precipitate. However, this effect is much more pronounced in the case of NS, as a result of its overly fine particle size, its dispersion state as well as its much higher surface area. Many studies have confirmed that the surface activity of NS with cement, during the hydration process, is much higher than that of SF and cement, as a result of which the consumption rate of $\mathrm{CH}$ is much higher in the case of NS. Moreover, the volume fraction of the high-stiffness $\mathrm{C}-\mathrm{S}-\mathrm{H}$ gel increases significantly in NS-modified specimens, as compared to SF-modified ones [15-17].

A noticeable difference in the hydration kinetics of specimens containing NS or SF can be seen in Fig. 1. An increment in the NS dosage resulted in an acceler-

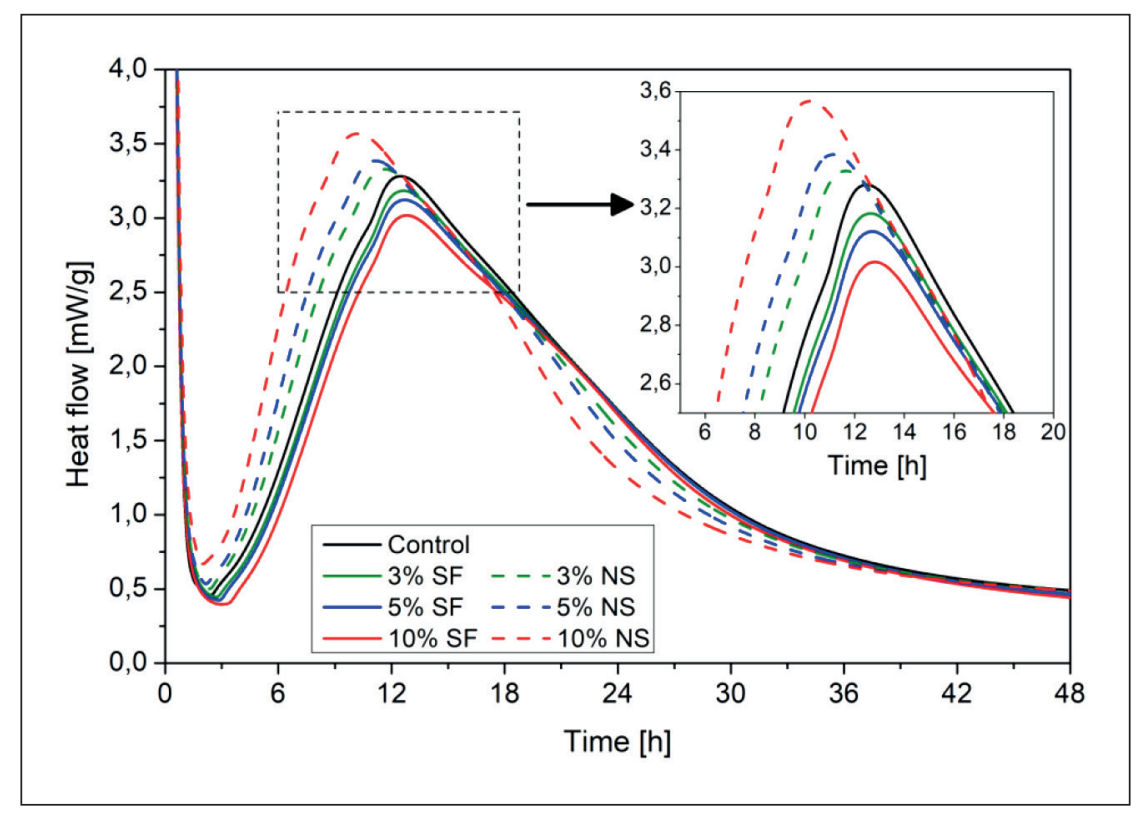

Fig. 1. Comparison of the heat flow of cement pastes with different NS and SF dosages 


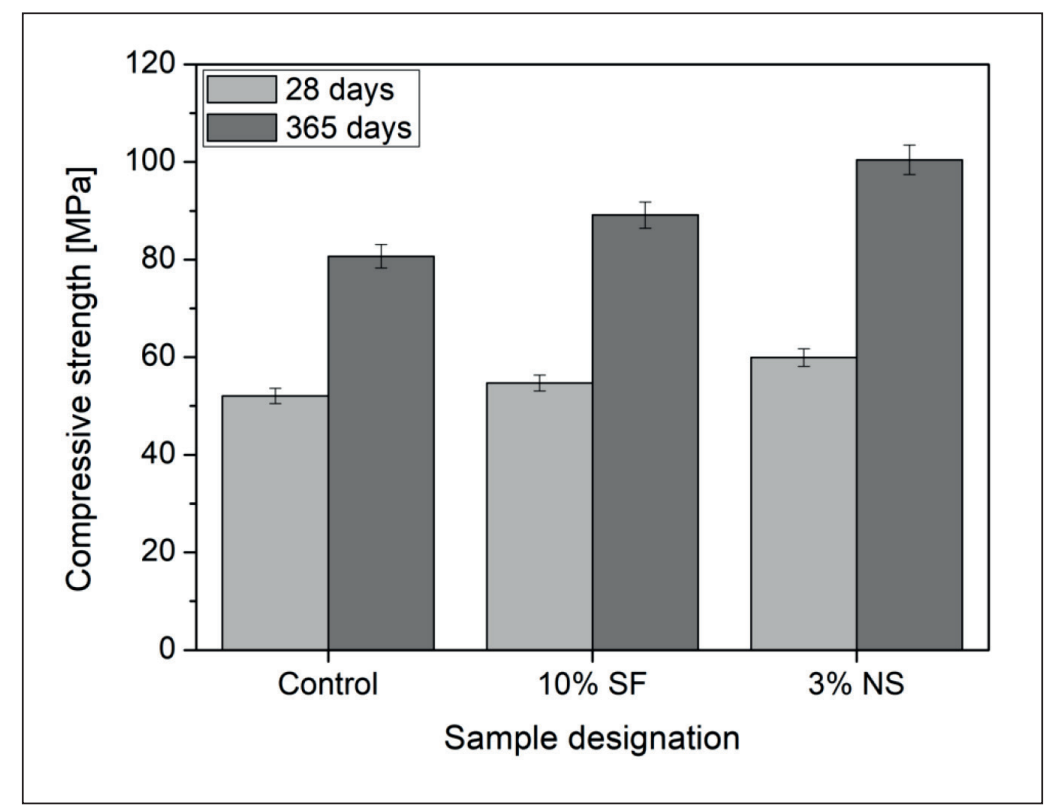

Fig. 2. Comparison of $\mathbf{2 8}$ and $\mathbf{3 6 5}$ days compressive strength of control mortar, mortars containing $10 \%$ bwoc of SF and $3 \%$ bwoc (determined on $40 \times 40 \times 40 \mathrm{~mm}^{3}$ specimens)

ated rate of cement hydration. Conversely, SF-modified specimens exhibited lower exothermic peak values [18, 19]. In addition, the presence of NS contributed to an acceleration in the appearance of the exothermic peak. The differences between the NS and SF interactions can be attributed to the activity of the particles as well as to their agglomeration. SF is usually incorporated into a mixture in dry, powdered form and mainly in high dosages (10\% bwoc). However, the incorporation of nanosilica is usually prolonged with ultrasound dispersion, or as in this case, it is incorporated in a stable suspension, thus facilitating proper particle dispersion. Even though the incorporation of $10 \%$ of NS is beneficial in accelerating the cement hydration process, numerous studies have confirmed that, despite beneficial effects in early cement hydration, an excessive NS dosage, later leads to a decrease in its positive effects because of the formation of agglomerations, problems with workability and the development of voids in the composites [7]. Therefore, based on previous studies as well as on the available literature, $3 \%$ bwoc of NS was chosen as an optimal dosage for the production of cement mortars in this study. Fig. 2 presents a comparison of the 28 and 365 day compressive strength values of pristine mortar and mortars containing the optimal NS dosage (3\% bwoc), or the commonly used SF dosage ( $10 \%$ bwoc). It can be clearly seen that mortars containing NS exhibited much higher improvement rates, both in terms of short term and long term performance.

\section{Results and discussion}

\subsection{Compressive strength after 28 days}

The compressive strengths of mortars, determined on $20 \times 20 \times 20 \mathrm{~mm}^{3}$ cubes, are presented in Fig. 3. The values are higher than those presented in Fig. 2, due to the socalled scale effect associated with a change in specimen sizes. Nevertheless, both the specimen sizes used in this study were appropriate for strength evaluations and there was good correlation between the values. The specimens containing the quartz and magnetite aggregates exhibited higher and relatively comparable compressive strength values, while the limestone and barite based mortars exhibited slightly lower strengths. In all cases nanosilica contributed to strength improvement, ranging from $13 \%$ to $23 \%$, depending on type of aggregate used. It was found that specimens containing the barite and limestone aggregates had better improvements that the ones with quartz or magnetite aggregates. Nevertheless, a clear improvement in compressive strength, as a result of the presence of NS, was confirmed.

\subsection{Thermogravimetric analysis (TGA)}

The results of TGA studies of the cement pastes, after 28 days of curing, are presented in Fig. 4. DTG data in a range of temperatures up to $600^{\circ} \mathrm{C}$, has also been presented, for the purposes of evaluation. Two clear peaks can 


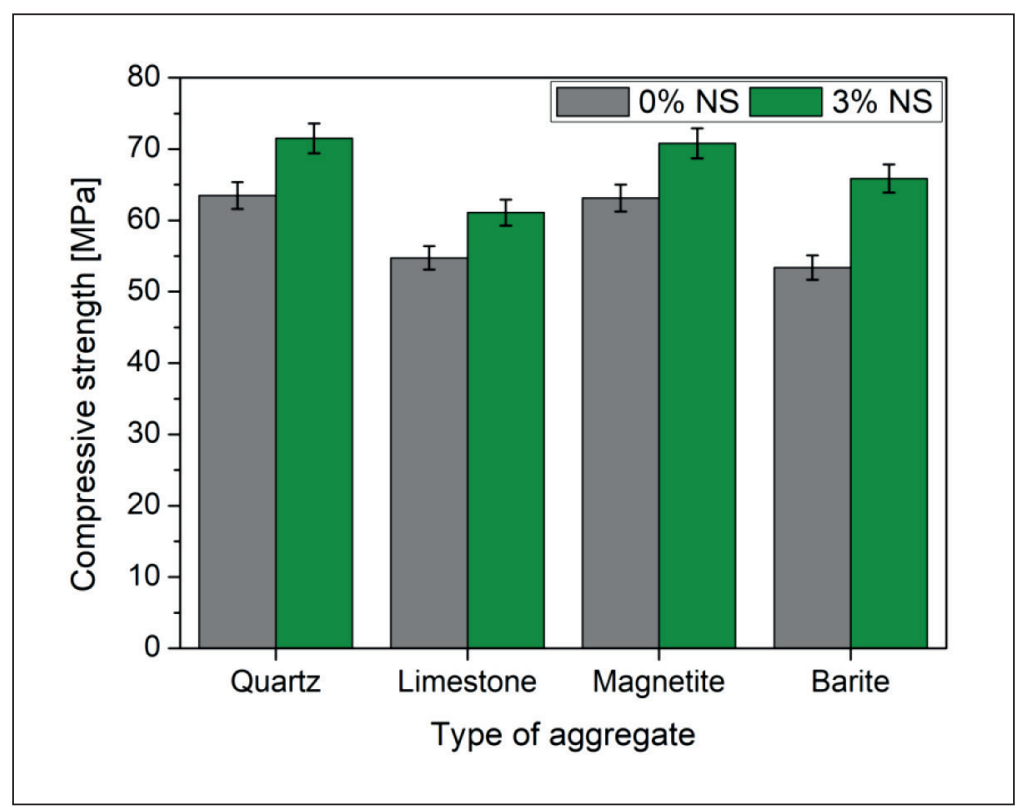

Fig. 3. Compressive strengths of mortars containing different aggregates, after 28 days of curing (determined on $20 \times 20 \times 20 \mathrm{~mm}^{3}$ specimens)

be distinguished within this range; according to the literature, the one in the range of $120-300^{\circ} \mathrm{C}$ corresponds to the dehydration of hydrates such as $\mathrm{C}-\mathrm{S}-\mathrm{H}$ and ettringite, thus giving a general indication of the $\mathrm{C}-\mathrm{S}-\mathrm{H}$ volume. The second peak, between $400-500^{\circ} \mathrm{C}$, is attributable to the de-hydration of $\mathrm{CH}$ (calcium hydroxide) $[20,21]$. It can be clearly seen, that specimens containing NS exhibited a higher mass loss in the first temperature range, thus confirming that more $\mathrm{C}-\mathrm{S}-\mathrm{H}$ was produced in the NS-modified specimen. In addition, a significantly lower peak is visible in the second range, indicating a sub- stantially lower $\mathrm{CH}$ content in the NS-modified specimen, thereby confirming that $\mathrm{CH}$ was consumed by NS in the pozzolanic reaction and that more $\mathrm{C}-\mathrm{S}-\mathrm{H}$ gel was produced.

\subsection{Mercury intrusion porosimetry (MIP)}

As evidenced by Fig. 5, which shows the pore size distributions of cement pastes with and without NS, the results of this study clearly show that NS alters the pore structures of pastes. Total cement paste porosity decreased

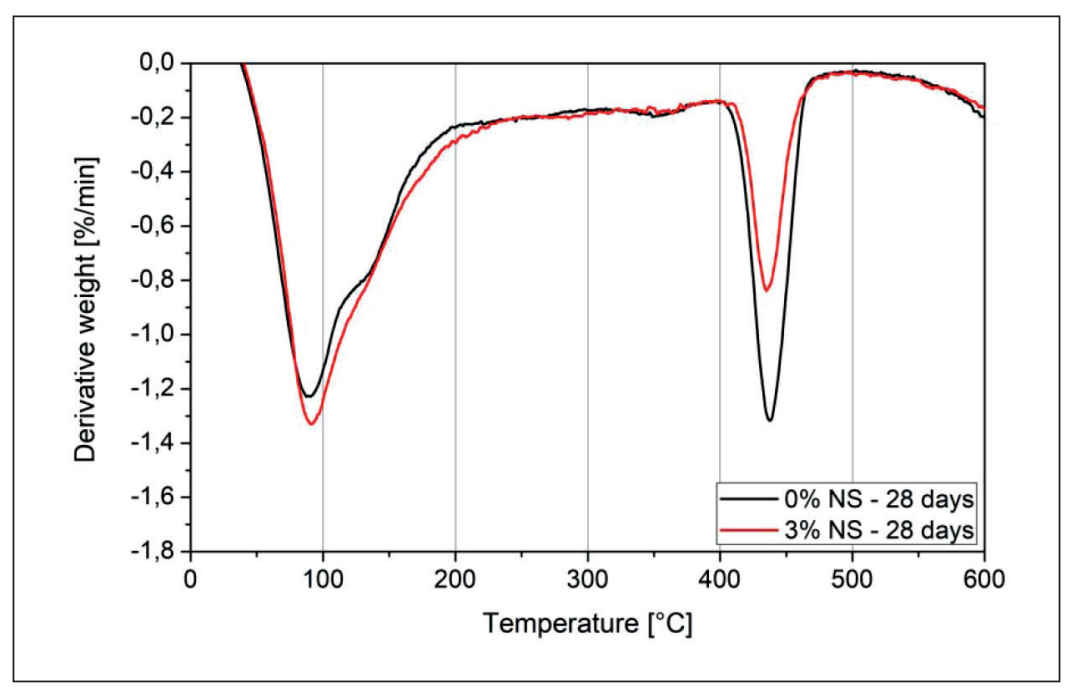

Fig. 4. DTG of pristine and NS-modified cement pastes after 28 days of curing 


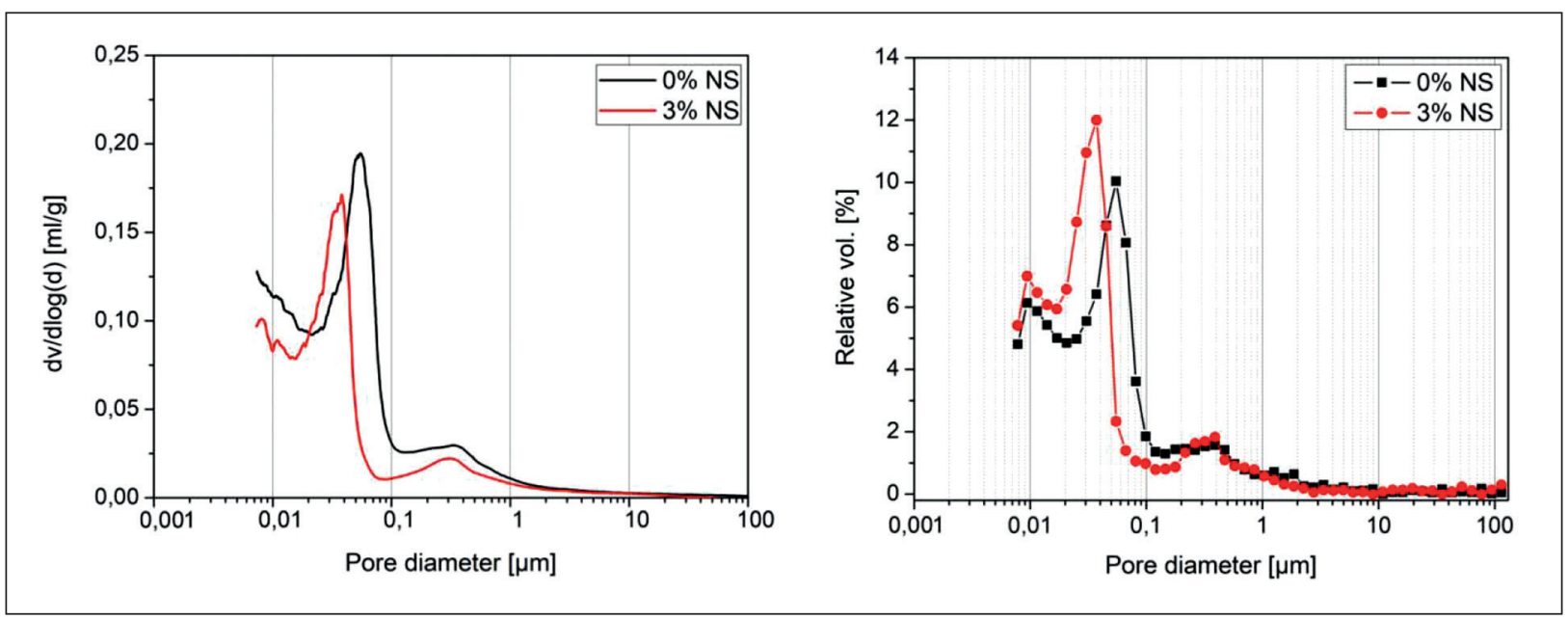

Fig. 5. Pore size distributions of specimens obtained with MIP studies

from $24.2 \%$ to $19.3 \%$, when NS was incorporated in it. In addition, a substantial reduction of pore diameter was reported in NS-modified specimens. According to different studies, the harmfulness of pores can be classified according to their diameters. Mehta and Monteiro [22] classifies pores in the following way: $d>0.10 \mu \mathrm{m}$ (more harmful pore), $d=0.05-0.10 \mu \mathrm{m}$ (harmful pore), $\mathrm{d}=0.0045-0.05 \mu \mathrm{m}$ (less harmful pore), $\mathrm{d}<0.0045 \mu \mathrm{m}$ (harmless pore). Conversely, Wu and Lian [23] classify pores into four types: $\mathrm{d}<0.02 \mu \mathrm{m}$ (harmless pore), $\mathrm{d}=$ 0.02-0.05 $\mu \mathrm{m}$ (less harmful pore), $\mathrm{d}=0.05-0.20 \mu \mathrm{m}$ (harmful pore), $\mathrm{d}>0.20 \mu \mathrm{m}$ (more harmful pore). In regard to these pore categorizations, it can be clearly seen that NS has a beneficial effect in reducing pore diameters, as well as in increasing the volume of smaller diameter pores, thus improving microstructure. Together with the TGA results above, these observations confirm that the presence of NS in a mixture results in the production of more $\mathrm{C}-\mathrm{S}-\mathrm{H}$ gel, thus producing a more compacted and refined cement matrix. This itself might be responsible for the compressive strength improvements reported above, in section 3.1.

\section{REFERENCES}

1. Matesová D., Bonen D., Shah SP. Factors affecting the resistance of cementitious materials at high temperatures and medium[0] heating rates. Materials and Structures 2006, vol. 39, no. 455. https://doi.org/10.1007/s11527-005-9041-4.

2. Kodur V., Khaliq W. Effect of temperature on thermal properties of different types of high-strength concrete. Journal of Materials in Civil Engineering. 2011, vol. 23, no. 6, pp. 793-801. DOI: 10.1061/(ASCE)MT.1943-5533.0000225.

3. Mendes A., Sanjayan J.G., Collins F. Long-term progressive deterioration following fire exposure of OPC versus slag blended cement pastes. Materials and Structures. 2009, vol. 42, no. 1, pp. 95-101. DOI: 10.1617/s11527-008-9369-7.

4. Sikora P., Abd Elrahman M., Stephan D. The influence of nanomaterials on the thermal resistance of cement-based composites-A review. Nanomaterials. 2018, vol. 8, no. 7. DOI: 10.3390/nano8070465.

5. Behnood A., Ziari H. Effects of silica fume addition and water to cement ratio on the properties of high-strength concrete after exposure to high temperatures. Cement and Concrete Composites. 2008, vol. 30, no. 2, pp. 106-112. DOI: 10.1016/j.cemconcomp.2007.06.003.

6. Ivanov L.A., Prokopiev P.S. The inventions in nanotechnologies as practical solutions. Part IV. Nanotechnologies in Construction. 2019, vol. 11, no. 4, pp. 447-457. DOI: 10.15828/2075-8545-2019-11-4-447-457.

7. Sikora P., Cendrowski K., Abd Elrahman M., Chung S-Y., Mijowska E., Stephan D. The effects of seawater on the hydration, microstructure and strength development of Portland cement pastes incorporating colloidal silica. Applied Nanoscience. 2019. DOI: 10.1007/s13204-019-00993-

8. Mendes A., Sanjayan J.G., Gates W.P., Collins F. The influence of water absorption and porosity on the deterioration of cement paste and concrete exposed to elevated temperatures, as in a fire event. Cement and Concrete Composites. 2012, vol. 34, no. 9, pp. 1067-1074. DOI: 10.1016/j.cemconcomp.2012.06.007. 
9. Yermak N., Pliya P., Beaucour A-L., Simon A., Noumowé A. Influence of steel and/or polypropylene fibres on the behaviour of concrete at high temperature: Spalling, transfer and mechanical properties. Construction and Building Materials. 2017, vol. 132, pp. 240-250. DOI: 10.1016/j.conbuildmat.2016.11.120.

10. Guelmine L., Hadjab H., Benazzouk A. Effect of elevated temperatures on physical and mechanical properties of recycled rubber mortar. Construction and Building Materials. 2016, vol. 126, pp. 77-85. DOI: 10.1016/j.conbuildmat.2016.09.018.

11. Ye Q., Zhang Z., Sheng L., Chen R. A comparative study on the pozzolanic activity between nano-SiO2 and silica fume. Journal of Wuhan University of Technology-Mater. Sci. Ed. 2006, vol. 21, pp. 153-157. DOI: 10.1007/BF02840907.

12. Krivenko P.V., Sanytsky M., Kropyvnytska T. The effect of nanosilica on the early strength of alkali-activated portland composite cements. Solid State Phenomena. 2019, vol. 296, pp. 21-26. DOI: 10.4028/www.scientific.net/SSP.296.21.

13. Hou P., Qian J., Cheng X., Shah S.P. Effects of the pozzolanic reactivity of nanoSiO2 on cement-based materials. Cement and Concrete Composites. 2015, vol. 55, pp. 250-258. DOI: 10.1016/j.cemconcomp.2014.09.014.

14. Potapov V.V., Efimenko Y.V., Gorev D.S. Determination of the amount of $\mathrm{Ca}(\mathrm{OH})_{2}$ bound by additive nano-SiO in cement matrices. Nanotehnologii v stroitel'stve $=$ Nanotechnologies in Construction. 2019, vol. 11, no. 4, pp. 415-432. DOI: 10.15828/2075-8545-2019-11-4-415-432.

15. Mondal P., Shah S.P., Marks L.D., Gaitero J.J. Comparative study of the effects of microsilica and nanosilica in concrete. Transportation Research Record. 2010 vol. 2141, no. 1, pp. 6-9. DOI: 10.3141/2141-02.

16. Kropyvnytska T., Sanytsky M., Rucinska T., Rykhlitska O. Development of nanomodified rapid hardening clinker-efficient concretes based on composite Portland cements. Eastern-European Journal of Enterprise Technologies. 2019, vol. 6(6), no. 102, pp. 38-48. DOI: 10.15587/1729-4061.2019.185111.

17. Biricik H., Sarier N. Comparative study of the characteristics of nano silica - silica fume - and fly ash - incorporated cement mortars. Materials Research. 2014, vol. 17, no. 3, pp. 570-582. DOI: 10.1590/S1516-14392014005000054.

18. Vance K., Aguayo M., Dakhane A., Ravikumar D., Jain J., Neithalath N. Microstructural, mechanical, and durability related similarities in concretes based on OPC and alkali-activated slag binders. International Journal of Concrete Structures and Materials. 2014, vol. 8, no. 4, pp. 289-299. DOI: 10.1007/s40069-014-0082-3.

19. Shi C., Wang D., Wu L., Wu Z. The hydration and microstructure of ultra high-strength concrete with cement-silica fume-slag binder. Cement and Concrete Composites. 2015, vol. 61, pp. 44-52. DOI: 10.1016/j.cemconcomp.2015.04.013.

20. Kim T., Hong S., Seo K-Y., Kang C. Characteristics of ordinary portland cement using the new colloidal nano-silica mixing method. Applied Sciences. 2019, vol. 9, no. 20, pp. 4358. DOI: 10.3390/app9204358.

21. Singh L.P., Goel A., Bhattachharyya S.K., Ahalawat S., Sharma U., Mishra G. Effect of morphology and dispersibility of silica nanoparticles on the mechanical behaviour of cement mortar. International Journal of Concrete Structures and Materials. 2015, vol. 9, no. 2, pp. 207-217. DOI: 10.1007/s40069-015-0099-2.

22. Mehta P.K., Monteiro P.J.M. Concrete: Microstructure, Properties, and Materials. New York, USA, McGraw-Hill, 2006.

23. Wu Z., Lian H. High Performance Concrete. Beijing, China, China Railroad Publishing Company, 1999.

The editorial Board plans to publish the continuation of the article and the list of references in the electronic edition «NANOTECHNOLOGIES IN CONSTRUCTION: A Scientific Internet-Journal» 2020, Vol. 12, no. 3.

\section{INFORMATION ABOUT THE AUTHOR}

Pawel Sikora, PhD, Assistant Professor, Department of Building Engineering, Faculty of Civil Engineering and Architecture, West Pomeranian University of Technology, Szczecin, Al. Piastow 50, 70-311 Szczecin, Poland and Postdoctoral researcher at Building Materials and Construction Chemistry, Technische Universität Berlin, Berlin, Gustav-Meyer-Allee 25, 13355 Berlin, Germany; pawel.sikora@zut.edu.pl 